\title{
Determination of the Diffusion Coefficient and the Activation Energy of Fluoroplastics
}

\author{
Lakel Abdelghani
}

Material Science Department, Faculty of Science, Biskra University, Biskra 07000, Algeria

Corresponding Author Email: a.lakel@univ-biskra.dz

https://doi.org/10.18280/acsm.440309

Received: 16 January 2020

Accepted: 20 March 2020

\section{Keywords:}

DSC, expanded graphite, nanotube, transition, heating rate, dispersion

\begin{abstract}
The aim of this research is to study four samples using the fluoroplastic scanning calorimeter which contain different concentrations of thermally extended graphite (GTD) in different dispersions. We noticed that the heating speed plays a very important role. Increasing the heating speed from 5 to 10 then $15^{\circ} \mathrm{C} / \mathrm{min}$, changes the thermal behavior of an infinitesimally small compound regardless of the concentration and/or dispersion. All curves each contain an anomaly in the calorimetric curves. The shape of the latter, its energizing energy, and its intensity depend on the concentration and dispersion. The temperature of anomalies in the calorimeter curve changes from one sample to another. We have shown that nanomaterials that contain the smallest GTD concentration with high dispersion and heat up at the highest heating speed deteriorate at high temperatures. It is more resistant to thermal shocks. One of the interesting results of this work the introduction of an amount of GTD in to the polymer improves the thermal properties of the infinitesimal compound, and its use becomes possible in a wide range of temperature.
\end{abstract}

\section{INTRODUCTION}

The technological development has resulted in new highquality materials with high performance and significantly longer life spans. The technical-commercial compromise is constantly improving. This became possible thanks to the new combinations of materials including the insertion of nanometric elements in various matrices, including polymers. Thus, the obtained nanocomposites used in the various fields are at the origin of the industrial progress and improvement of the properties of the current used machines.

In recent decades, obtaining polymer composites reinforced by carbon fiber, carbon foam, graphite or carbon nanotubes have been the subject of several studies and the publication of numerous research projects [1-9].

The development of thermally expanded graphite (GTD) and its insertion in polymer matrices have considerably increased the service life of mechanical parts by improving certain properties such as increasing compressibility and decreasing the coefficient of friction. Light weight and inexpensive polymer materials made it possible to replace heavy and expensive mechanical parts with nanocomposites reinforced with thermally expanded graphite [7].

It is not only used in the mechanical industry but has become indispensable in other sectors such as energetics, environmental protection, medicine. Its wide spectrum of use makes it very competitive compared to other materials.

The addition of the GTD in a nanocomposite also favors the decrease of the percolation concentration [8], raises the electrical conductivity [9-11], render sit thermally stable [1220] and delays the appearance of the vitreous phase. This characteristic makes the material usable in a wider temperature range before its degradation [21-28].

The different thermophysical treatments are important actors and are responsible for the properties of nanomaterials. The choice of the treatment they must undergo is essential since they give them the physical characteristics allowing them to be used according to the conditions of the environment.

The aim of this work is to study the role of the heating rate and the influence of two essential parameters, the GTD concentration and its dispersion since they are responsible for the physical properties and play a fundamental role in the choice of the polymer.

We took fluoroplastic in which we introduced thermally expanded graphite (GTD) at several concentrations and different degrees of dispersion.

We have chosen differential calorimetry as an experimental technique to be able to follow the evolution of the transition temperature of the vitreous phase and thus to have information concerning the degradation of the nanocomposite studied.

We took 04 samples containing different concentrations of GTD. The dispersion differs from one sample to another (Table 1).

The DSC measurements were made in the $0-350^{\circ} \mathrm{C}$ temperature range using a Setaram 92 DSC. Three heating rates were considered to be 5,10 and $15^{\circ} \mathrm{C} / \mathrm{min}$.

Table 1. Concentration and dispersion of GTD in the samples

\begin{tabular}{ccccc}
\hline Sample & 20GTD60(E1) & 20GTD60-100(E2) & 5GTD60-100(E3) & 10GTD60(E4) \\
\hline \%GTD & 20 & 20 & 5 & 10 \\
Dispersion & $<60 \mu$ & $60-100 \mu$ & $60-100 \mu$ & $<60 \mu$ \\
\hline
\end{tabular}




\section{RESULTS AND DISCUSSION}

The results obtained show that all the DSC curves have the same overall appearance and show an endothermic peak around $220^{\circ} \mathrm{C}$ (see Figure 1). This peak is attributed to the devitrification of the samples. The shape and intensity of this peak change from one sample to another.

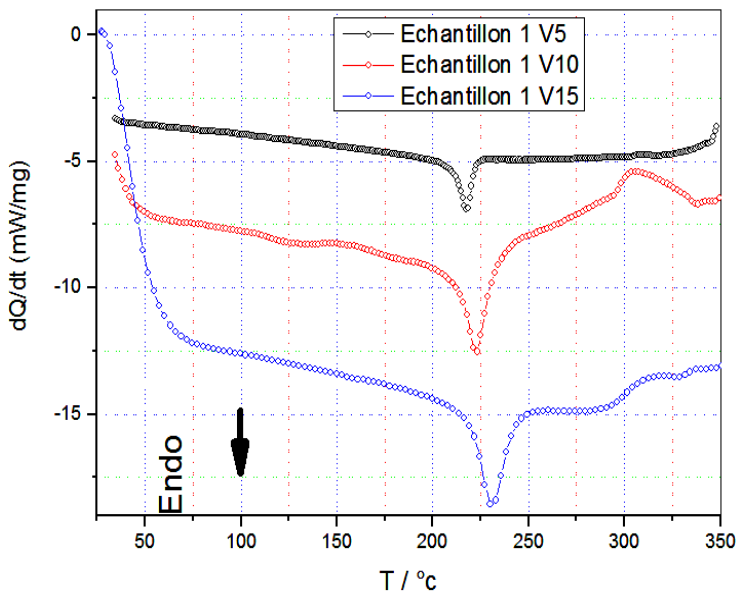

(a) Sample 1

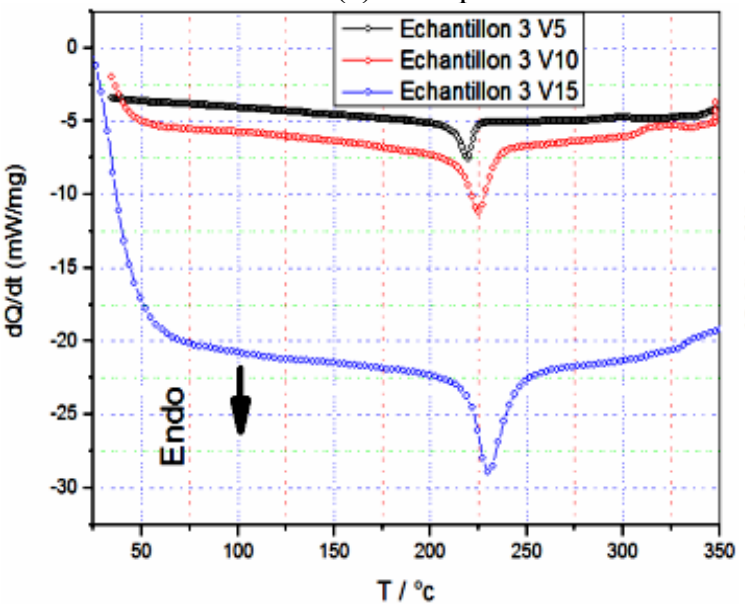

(c) Sample 3
In general, the increase in the heating rate causes the intensification of the calorimetric anomaly and a decrease in the values of the DSC whatever the sample.

For the same rate, the endothermic peak appears at almost the same temperature with different intensities depending on the GTD concentration and dispersion (Figures 2, 3 and 4).

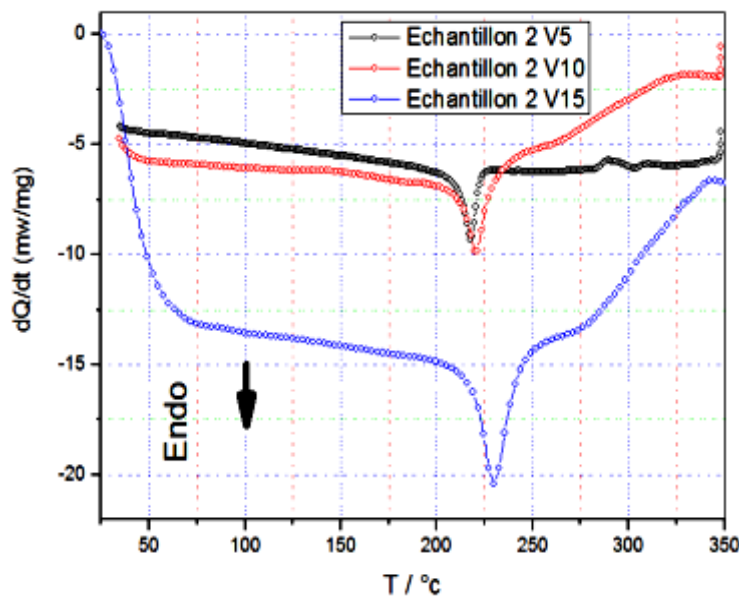

(b) Sample 2

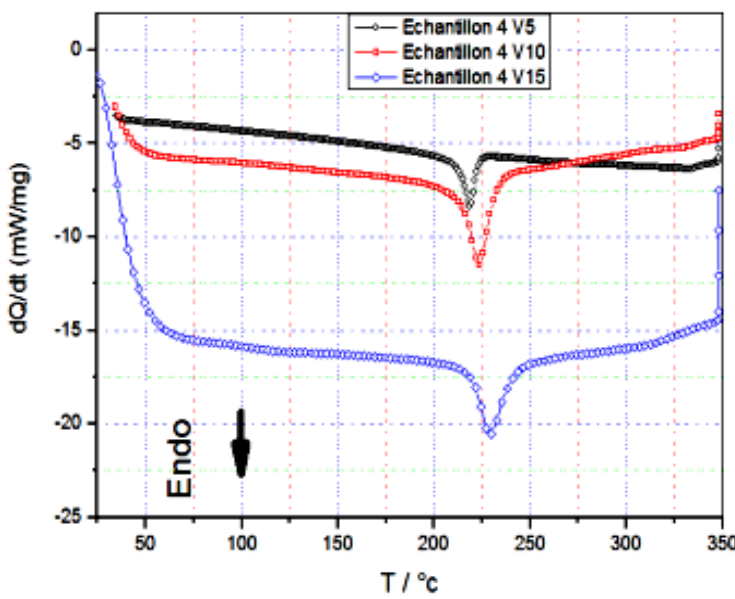

(d) Sample 4

Figure 1. DCS curves of sample 4 obtained with tree heating rates $\left(5{ }^{\circ} \mathrm{C} / \mathrm{min}, 10{ }^{\circ} \mathrm{C} / \mathrm{min}\right.$ and $\left.15{ }^{\circ} \mathrm{C} / \mathrm{min}\right)$

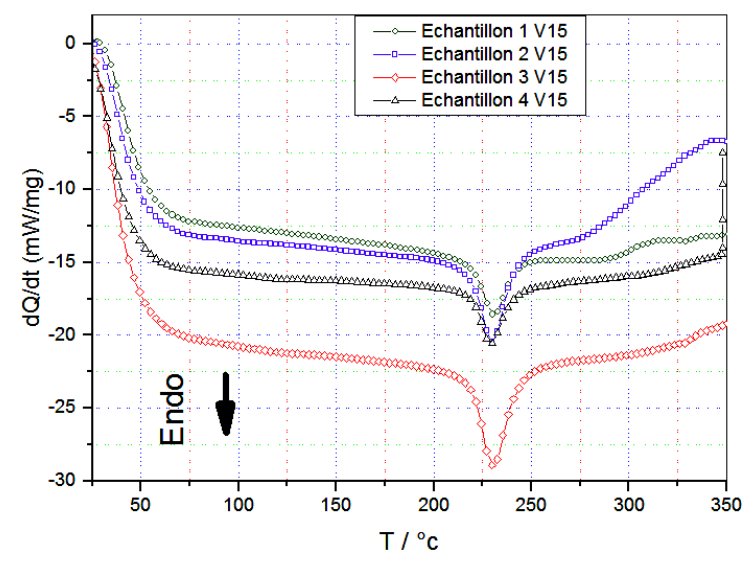

Figure 2. DSC curves of the four samples obtained for $\mathrm{V}=15^{\circ} \mathrm{C} / \mathrm{min}$

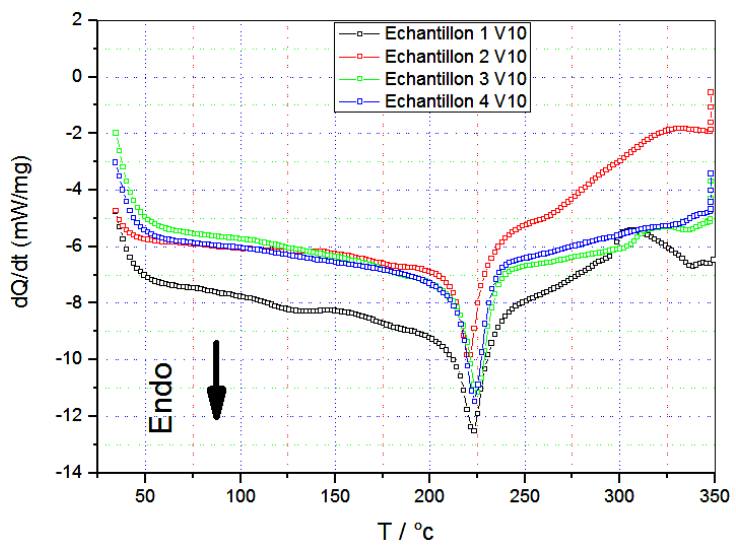

Figure 3. DSC curves of the four samples obtained for $\mathrm{V}=10^{\circ} \mathrm{C} / \mathrm{min}$ 


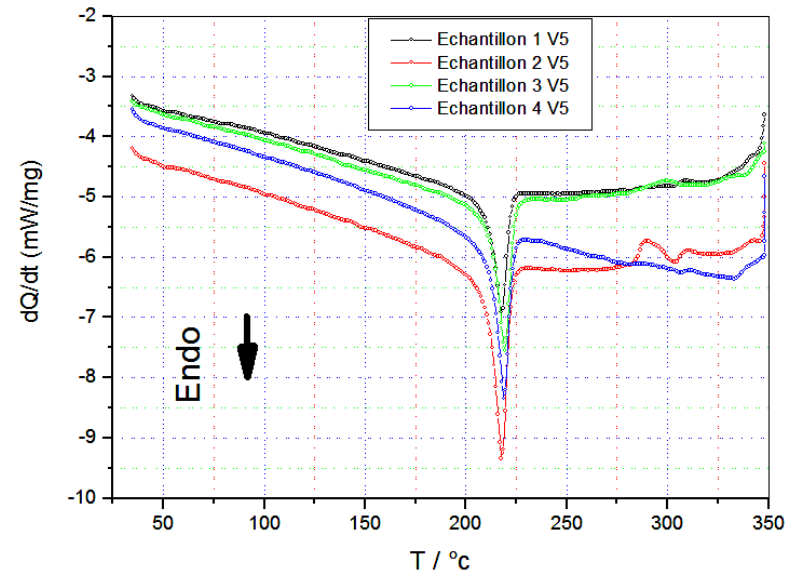

Figure 4. DSC curves of the four samples obtained for $\mathrm{V}=5{ }^{\circ} \mathrm{C} / \mathrm{min}$

As the heating rate increases $\left(5^{\circ} \mathrm{C} / \mathrm{min}, 10^{\circ} \mathrm{C} / \mathrm{min}\right.$ and $15{ }^{\circ} \mathrm{C} / \mathrm{min}$ ) the peaks are shifted to higher temperatures respectively $\left(218^{\circ} \mathrm{C} ; 222^{\circ} \mathrm{C}\right.$ and $\left.230^{\circ} \mathrm{C}\right)$.

The intensities of all peaks also increase with increasing heating rates. The highest intensities occur at a rate of $15^{\circ} \mathrm{C} / \mathrm{min}$ whereas the highest intensity value is observed for the 5 GTD 100 sample containing 5\% GTD with a dispersion of between 60 and $100 \mu \mathrm{m}$. Similarly, the smallest intensities are observed at the lowest rate of $5{ }^{\circ} \mathrm{C} / \mathrm{min}$ and the minimum value of- $7.0 \mathrm{~mW} / \mathrm{mg}$ corresponds to the 20 GTD 60 sample containing 20\% TEG and a dispersion lower than $60 \mu \mathrm{m}$ (see Table 2).

In general, it can be seen that for the same concentration of GTD and a different dispersion, the peaks appear at the same temperature for a given speed. However, the peaks corresponding to the $60-100 \mu \mathrm{m}$ dispersion are more intense.

In the same way, it is found that for a given dispersion, the peak of the sample containing the smallest concentration is the most intense.

Considering the various samples between them, it is noted that for the sample 1, the differences in the values of the DSC for the different speeds are constant, while for the other samples 2, 3 and 4, a different behavior is observed. Indeed, the curves measured at speeds of 5 and $10{ }^{\circ} \mathrm{C} / \mathrm{min}$ overlap. The curve corresponding to the speed of $15{ }^{\circ} \mathrm{C} / \mathrm{min}$ is totally detached from those of the two previous ones. The peaks are the most intense at this speed. We also found that the increase in dispersion is causing a strong intensification of the calorimetric anomaly when the heating rate is $15^{\circ} \mathrm{C} / \mathrm{min}$.

Decreasing the heat ingrate makes the peak intensity of the DSC clearly decrease.

As heating rates increase and GTD concentrations decrease, the calorimetric anomaly is at least twice as great. The variations of the DSC curve become monotonous on both sides of the peak.

For the same concentration equal to $20 \%$ in GTD, we noticed that when the dispersion passes from the smallest value $(<60 \mu \mathrm{m})$ to the higher value $(60-100 \mu \mathrm{m})$ the intensities of the calorimetric peaks increase whatever the heating rate. From the point of view of the heating rate, we find that the curve corresponding to the speed of $15^{\circ} \mathrm{C} / \mathrm{min}$ is completely detached from the other two. For the dispersion of $60-100 \mu \mathrm{m}$, the curves obtained with the heating rates of 5 and $10{ }^{\circ} \mathrm{C} / \mathrm{min}$ have the same pace up to $230^{\circ} \mathrm{C}$, then we see a sharp increase of the DSC for the speed of $10{ }^{\circ} \mathrm{C} / \mathrm{min}$. At $350^{\circ} \mathrm{C}$, the difference between the two curves is close to $100 \%$. The following figure (Figure 5), shows that $15^{\circ} \mathrm{C} / \mathrm{min}$ and they stand out completely from the others obtained at speeds of 5 and $10{ }^{\circ} \mathrm{C} / \mathrm{min}$.

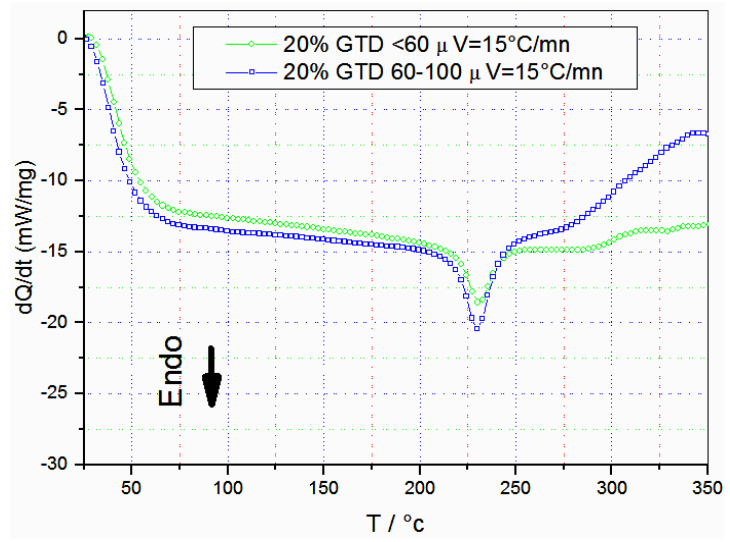

Figure 5. DSC curves of samples containing the same concentration of GTD and having different dispersions

For dispersion $(60-100 \mu \mathrm{m})$, the concentration of GTD has effects on the peak of the DSC curves. When the difference between the concentrations is large (5\% and 20\%), the anomaly intensities increase with the increase in the heating rate. Whatever the rate of heating, the material with less GTD has the peak of the highest DSC and the largest DSC values. When the concentration is (10\% and $20 \%)$, the peak intensities also increase with increasing heating rate and are highest when the heating rate is greatest $\left(15^{\circ} \mathrm{C} / \mathrm{min}\right)$, Figure 6 .

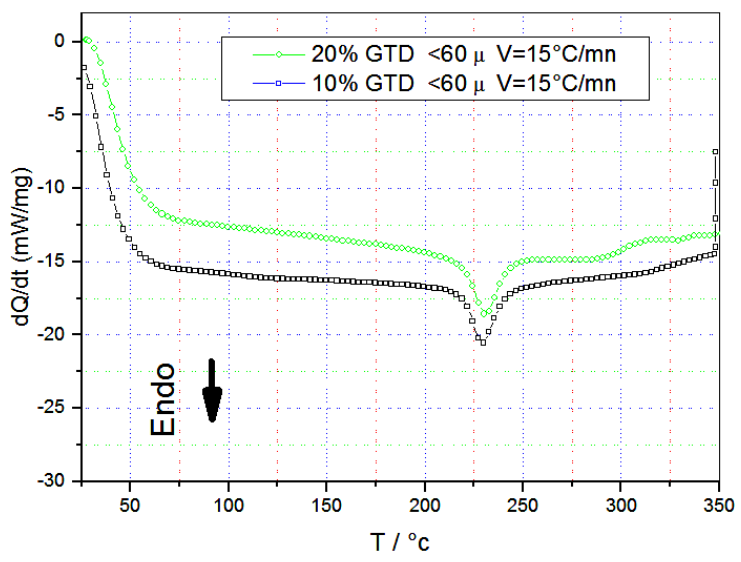

Figure 6. DSC curves of samples having the same dispersion at different concentrations of GTD

Table 2. Peak intensities by concentration and dispersion of GTDs

\begin{tabular}{ccccc}
\hline Samples & 20 GTD 60 $(\mathrm{mW} / \mathrm{mg})$ & 20 GTD 60-100 $(\mathrm{mW} / \mathrm{mg})$ 5 GTD 60-100 $(\mathrm{mW} / \mathrm{mg}) \mathbf{1 0}$ GTD 60 $(\mathrm{mW} / \mathrm{mg})$ \\
\hline V5 & -7.0 & -9.2 & -7.5 & -8.4 \\
V10 & -12.5 & -10.0 & -11.3 & -11.4 \\
V15 & -18.6 & -20.5 & -29.0 & -20.6 \\
\hline
\end{tabular}




\section{DETERMINATION \\ OF \\ THE \\ ACTIVATION \\ ENERGY}

To calculate the activation energy (Ea) we used the three methods of Kissinger (KAS), and Ozawa, and Boswell [29, 30]. Determining the activation energy of a system from the evolution of the Minimal temperature of the endothermic peak (Tpic), as a function of the velocity $\mathrm{V}$, by the following relations:

$$
\begin{gathered}
\mathrm{Y}=\ln \frac{\mathrm{V}}{\mathrm{T}_{\mathrm{PIC}}}=-\frac{\mathrm{E}}{\mathrm{T}_{\mathrm{PIC}} \mathrm{R}}+\mathrm{C} \\
\mathrm{Y}=\ln \mathrm{V}=-1.0518\left(\frac{\mathrm{E}}{\mathrm{T}_{\mathrm{PIC}} \mathrm{R}}\right)+\mathrm{C}_{1} \\
\mathrm{Y}=\ln \frac{\mathrm{V}}{\mathrm{T}_{\mathrm{PIC}}}=-\frac{\mathrm{E}}{\mathrm{T}_{\mathrm{PIC}} \mathrm{R}}+\mathrm{C}_{2}
\end{gathered}
$$

where,

$\mathrm{C}, \mathrm{C}_{1}$ and $\mathrm{C}_{2}$ are constants.

$\mathrm{E}$ : activation energy $(\mathrm{KJ} / \mathrm{mol})$.

$\mathrm{R}$ : Perfect gaz constant $(8.314 \mathrm{KJ} / \mathrm{mol} . \mathrm{K})$.

The activation energy (Ea) is obtained from the slope of the line $\mathrm{Y}$ as a function of (1/Tpic) where $\mathrm{C}, \mathrm{C}_{1}$ and $\mathrm{C}_{2}$ are constants. The line was drawn using the original software by the linear fit option (Figure 7, 8, 9 and10).

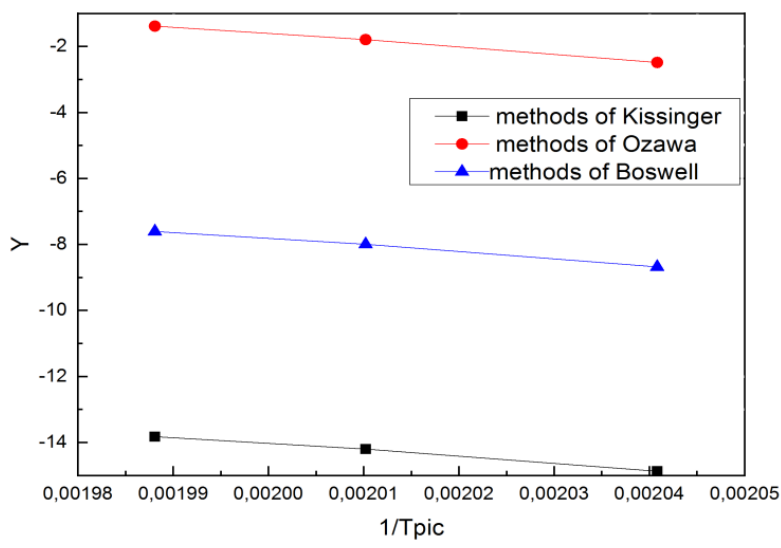

Figure 7. Activation energies of fluoroplastics containing $20 \%$ GTD with dispersion $(<60 \mu \mathrm{m})$

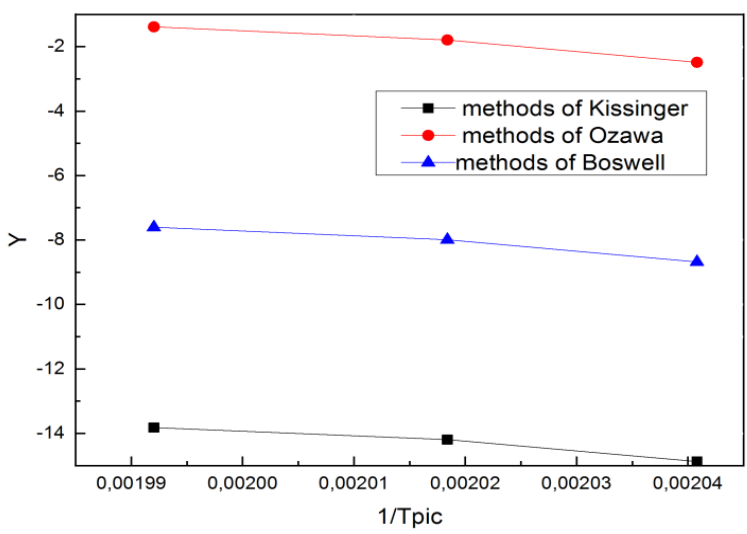

Figure 8. Activation energies of fluoroplastics containing $20 \%$ GTD with dispersion $(60-100 \mu \mathrm{m})$

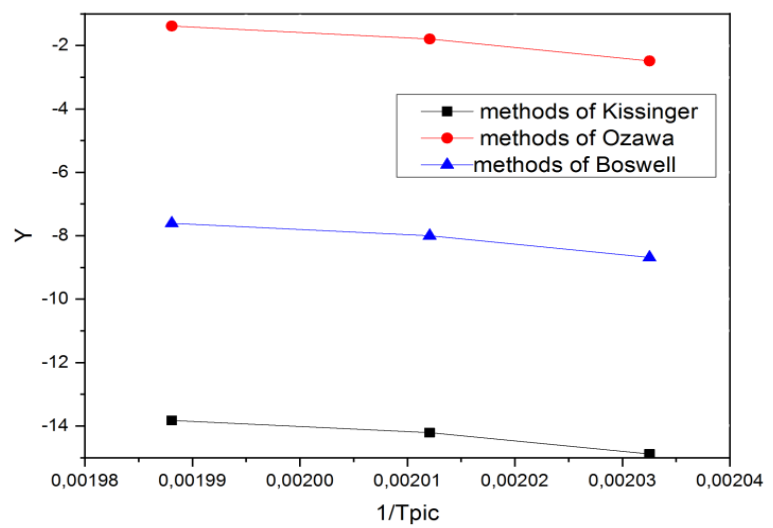

Figure 9. Activation energies of fluoroplastics containing 5\% GTD with dispersion $(60-100 \mu \mathrm{m})$

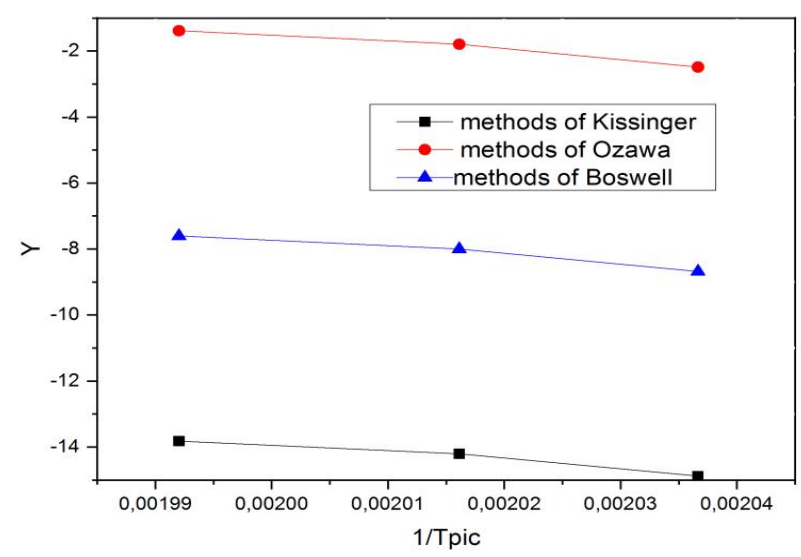

Figure 10. Activation energies of fluoroplastics containing $10 \%$ GTD with dispersion $(<60 \mu \mathrm{m})$

The calculation of the activation energy of 4 samples for the speed $\mathrm{V}=5^{\circ} \mathrm{C} / \mathrm{min}$ by the three methods are very close. The values of the energies are grouped in Table 3 .

\begin{tabular}{|c|c|c|}
\hline $\mathrm{E}_{\mathrm{a}}(\mathrm{mW} / \mathrm{mg})$ & Kissinger Ozawa & Boswell \\
\hline 20 GTD 60 & $-3.5 \pm 2.05-7.0 \pm 1.77$ & $-5.0 \pm 1.71$ \\
\hline 20 GTD $60-10$ & $-7.91 \pm 5.00-9.2 \pm 4.8$ & $-5.5 \pm 4.92$ \\
\hline 5 GTD $60-100$ & $-7.26 \pm 1.88-7.4 \pm 2.17$ & $-7.5 \pm 7.71$ \\
\hline 10 GTD 60 & $-4.14 \pm 2.05-8.4 \pm 3.00$ & $-6.21 \pm 2.71$ \\
\hline
\end{tabular}

Table 3. Peak intensities by concentration and dispersion of GTD

Table 4 reports the activation energy determined by three different methods of the four samples for the speed $\mathrm{V}=10^{\circ} \mathrm{C} / \mathrm{min}$.

Table 4. Peak intensities by concentration and dispersion of GTD

\begin{tabular}{cccc}
\hline $\mathbf{E}_{\mathbf{a}}(\mathbf{m W} / \mathbf{m g})$ & Kissinger & Ozawa & Boswell \\
\hline 20 GTD 60 & $-11.5 \pm 1.76$ & $-12.5 \pm 1.05$ & $-10.0 \pm 2.01$ \\
20 GTD 60 - 100 & $-8.89 \pm 2.21$ & $-10.0 \pm 3.19-11.2 \pm 2.71$ \\
5 GTD 60 - 100 & $-10.3 \pm 2.05$ & $-11.3 \pm 2.24$ & $-9.5 \pm 1.33$ \\
10 GTD 60 & $-11.14 \pm 3.11-11.4 \pm 2.28-8.49 \pm 1.01$ \\
\hline
\end{tabular}

Table 5 reports the activation energy determined by the three methods of the four samples for the speed $\mathrm{V}=15^{\circ} \mathrm{C} / \mathrm{min}$. 
Table 5. Peak intensities by GTD concentration and dispersion

\begin{tabular}{cccc}
\hline $\mathbf{E}_{\mathbf{a}}(\mathbf{m W} / \mathbf{m g})$ & Kissinger & Ozawa & Boswell \\
\hline 20GTD60(E1) & $-16.6 \pm 5.02$ & $-18.6 \pm 4.05$ & $-15.0 \pm 4.71$ \\
20GTD60-100(E2) & $-19.8 \pm 1.08$ & $-20.5 \pm 2.05$ & $-19.2 \pm 7.71$ \\
5GTD60-100(E3) & $-25.0 \pm 2.05$ & $-29.0 \pm 1.43$ & $-30 \pm 0.89$ \\
10GTD60(E4) & $-18.6 \pm 6.25$ & $-20.6 \pm 4.08$ & $-18.4 \pm 5.22$ \\
\hline
\end{tabular}

\section{OTHER RESULTS}

In the same context, additional analyzes concerning microstructures, X-ray diffraction, the influence of pressing, measurements of the parameters of the network before and after annealing as a function of the pressure, the stress and the degree of crystallinity were carried out. The results obtained are summarized below.

Figure 11 shows the microstructures of thermally expanded graphite and fluoroplastic-based nanocomposites containing GTD.

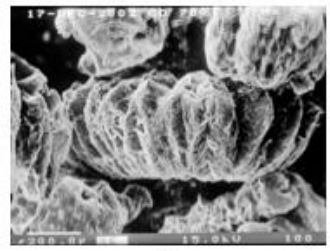

a)

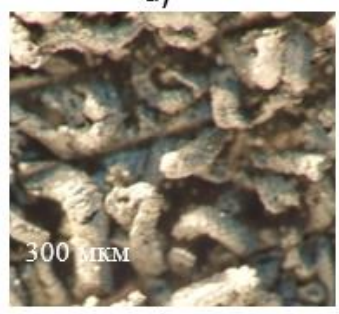

c)

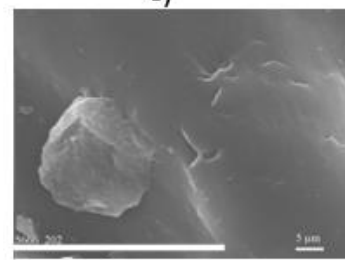

e)

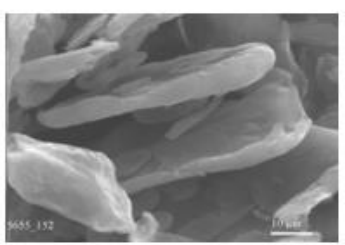

b)

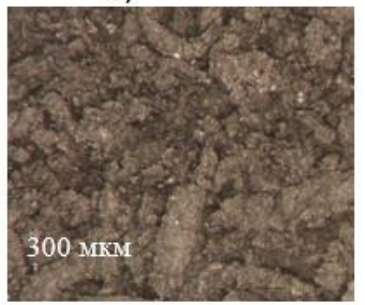

d) (a) GTD particles with dispersion down to 40 microns, (b, c, d and e.) Fluoroplastic-GTD mixture 5\% (vol.) At different magnifications

Figure 11. Microstructure of GTD particles

\section{CONCLUSION}

The results obtained in this work are essential since they illustrate the positive role of the addition of thermally expanded graphite in a polymer matrix. The degradation temperature of the finished product has shifted to high temperatures. So, its use has become possible under less favorable conditions (high temperature, friction, wear, ...) This result is confirmed by the measurements of other physical quantities favored the formation of clusters and the increase of the elastic limit which are responsible for the improvement of the mechanical properties.

We have shown that the DSC curve obtained for the heating rate of $15{ }^{\circ} \mathrm{C} / \mathrm{min}$ is the most important whatever the concentration and dispersion in GTD. All curves have a calorimetric anomaly whose activation energy and intensity and onset temperature vary with dispersion and GTD concentration. For the heating rate of $15^{\circ} \mathrm{C} / \mathrm{min}$, the DSC curve of the sample containing 5\% GTD and the $60-100 \mu \mathrm{m}$ dispersion shows the most intense peak and its temperature of appearance is the highest. So, this sample is the one that is the most resistant to thermal shocks and degrades the least in front of the other three.

We noticed that when the heating is carried out with the speed of $15{ }^{\circ} \mathrm{C} / \mathrm{min}$, the influence the dispersion (samples containing the same concentration in GTD and having two different dispersions: $<60$ and $60-100 \mu \mathrm{m}$ ) results in the largest DSC values. The intensities of the calorimetric peaks are also the most intense.

Comparison between two samples with the same dispersion and two different concentrations also shows that the DSC values and the activation energies and the intensities of the peaks obtained are much greater when the heating rate is $15^{\circ} \mathrm{C} / \mathrm{min}$ before those obtained when the speeds are 5 and $10{ }^{\circ} \mathrm{C} / \mathrm{min}$.

\section{ACKNOWLEDGMENT}

This work is supported by the Ministry of Higher Education and Scientific Research of the State of Algeria, as I thank Professor Revo, S.L from Ocarina who helped us with the experimental work.

\section{REFERENCES}

[1] Tagne, M., Zoulalian, A., Njomo, D., Bonoma, B. (2011). Modelisation of desorption isotherms and estimation of the thermophysic and thermodynamic properties of tropical woods in Cameroon: The case of Ayous and Ebony woods. Revue des Energies Renouvelables, 14(3): 487-500.

[2] Gary, D.P., Bynum, S., Thompson, B.D., Groce, B.R., Sagona, A., Hoffman, I.M., Garcia, C., Weber, C., Pojman, J.A. (2020). Thermal transport and chemical effects of fillers on free-radical frontal polymerization. Journal of Polymer Science, 58(16): 2151-2291. https://doi.org/10.1002/pol.20200323

[3] Craster, B., Jones, T.G.J. (2019). Permeation of a range of species through polymer layers under varying conditions of temperature and pressure: In situ measurement methods. Polymers, 11(6): 1056. https://doi.org/10.3390/polym11061056

[4] Dixon-Garrett, S.V., Nagai, K., Freeman, B.D. (2000). Ethylbenzene solubility, diffusivity, and permeability in poly(dimethylsiloxane). Journal of Polymer Science Part B: Polymer Physics, 38(11): 1417-1574. https://doi.org/10.1002/(SICI)10990488(20000601)38:11<1461::AID-POLB60>3.0.CO;2$\mathrm{H}$

[5] Nsouandele, J.L., Bonoma, B., Simo Tagne, M., Njomo, D. (2010). Determination of the diffusion coefficient of water in tropical woods. Phys. Chem. News, 54: 61-67.

[6] Dorbani, T., Zerrouk, I., Aouabdia, Y., Taleb, K., Boubertakh, A., Hamamda, S.J. (2010). Influence of the pressing direction on thermal expansion coefficient of 
graphite foam. Journal of Thermal Analysis and Calorimetry, 102(2): 667-670. https://doi.org/10.1007/s10973-010-0686-z

[7] Figueiredo, M., Henriques, J., Martins, G., Guerra, F., Judas, F., Figueiredo, H. (2010). Physicochemical characterization of biomaterials commonly used in dentistry as bone substitutes--comparison with human bone. Journal of Biomedical Materials Research Part B: Applied Biomaterials, 92(2): 409-419. https://doi.org/10.1002/jbm.b.31529

[8] Prusty, G., Swain, S.K. (2012). Dispersion of expanded graphite as nanoplatelets in a copolymer matrix and its effect on thermal stability, electrical conductivity and permeability. New Carbon Materials, 27(4): 271-277. https://doi.org/10.1016/S1872-5805(12)60017-1

[9] Tavman, I., Aydogdu, Y., Kök, M., Turgut, A., Ezan, A. (2011). Measurement of heat capacity and thermal conductivity of HDPE/expanded graphite nanocomposites by differential scanning calorimetry. Archives of Materials Science and Engineering, 50(1): 56-60.

[10] Kostić, R., Romčević, M., Romčević, N., Klopotowski, L., Kossut, J., Kuljanin-Jakovljević, J., Čomor, M.I., Nedeljković, J.M. (2008). Photoluminescence and farinfrared spectroscopy of PbS quantum dots-Polyvinyl alcohol nanocomposite. Optical Materials, 30(7): 11771182. https://doi.org/10.1016/j.optmat.2007.05.044

[11] Moniruzzaman, M., Winey, K.I. (2006). Polymer Nanocomposites Containing Carbon Nanotubes. Journal of Macromolecules, 39(16): 5194-5205. https://doi.org/10.1021/ma060733p

[12] Feng, C., Ni, H., Chen, J., Yang, W. (2016). Facile method to fabricate highly thermally conductive graphite/PP composite with network structures. ACS Applied Materials \& Interfaces, 8(30): 19732-19738. https://doi.org/10.1021/acsami.6b03723

[13] Goyal, R.K., Jagadale, P.A., Mulik, U.P. (2009). Thermal, mechanical, and dielectric properties of polystyrene/expanded graphite nanocomposites. Journal of Applied Polymer Science, 111(4): 2071-2077 https://doi.org/10.1002/app.29042

[14] Swain, S.K., Prusty, G., Ray, A.S., Behera, L. (2014). Dispersion of nanoplatelets of graphite on PMMA matrix by in situ polymerisation technique. Journal of Experimental Nanoscience, 9(3): 240-248. https://doi.org/10.1080/17458080.2012.654475

[15] Gantayat, S., Prusty, G., Rout, D.R., Swain, S.K. (2015). Expanded graphite as a filler for epoxy matrix composites to improve their thermal, mechanical and electrical properties. New Carbon Materials, 30(5): 432 437. https://doi.org/10.1016/S1872-5805(15)60200-1

[16] Zhao, Y.F., Xiao, M., Wang, S.J., Ge, X.C., Meng, Y.Z. (2007). Preparation and properties of electrically conductive PPS/expanded graphite nanocomposites. Composites Science and Technology, 67(11-12): 25282534. https://doi.org/10.1016/j.compscitech.2006.12.009

[17] Kuljanin-Jakovljević, J., Marinović-Cincović, M., Stojanović, Z., Krklješ, A., Abazović, N.D., Čomor, M.I. (2009). Thermal degradation kinetics of polystyrene/cadmium sulfide composites. Polymer Degradation and Stability, 94(6): 891-897. https://doi.org/10.1016/j.polymdegradstab.2009.03.004

[18] Vaziri, H.S., Omaraei, I.A., Abadyan, M., Mortezaei, M.,
Yousefi, N. (2011). Thermophysical and rheological behavior of polystyrene/silica nanocomposites: Investigation of nanoparticle content. Materials \& Design, 32(8-9): 4537-4542. https://doi.org/10.1016/j.matdes.2011.01.022

[19] Bera, O., Pilić, B., Pavličević, J., Jovičić, M., Holló, B., Szécsényi, K.M., Špirkova, M. (2011). Preparation and thermal properties of polystyrene/silica nanocomposites. Thermochimica Acta, 515(1-2): 1-5. https://doi.org/10.1016/j.tca.2010.12.006

[20] Park, S., Dikin, D.A., Nguyen, S.T., Ruoff, R.S. (2009). Graphene oxide sheets chemically cross-linked by polyallylamine. The Journal of Physical Chemistry C, 113(36): https://doi.org/10.1021/jp907613s

15801-15804.

[21] Xia, L., Zhang, P., Wang, R.Z. (2010). Preparation and thermal characterization of expanded graphite/paraffin composite phase change material. Carbon, 48(9): 25382548. https://doi.org/10.1016/j.carbon.2010.03.030

[22] Figueiredo, M., Fernando, A., Martins, G., Freitas, J., Judas, F., Figueiredo, H. (2010). Effect of the calcination temperature on the composition and microstructure of hydroxyapatite derived from human and animal bone. Ceramics International, 36(8): 2383-2393. https://doi.org/10.1016/j.ceramint.2010.07.016

[23] Ash-Kurlander, U., Martin, O., Fontana, L.D., Patil, V.R., Bernegger, M., Mondelli, C., Pérez-Ramírez, J., Steinfeld, A. (2016). Impact of daily startup-shutdown conditions on the production of solar methanol over a commercial $\mathrm{Cu}-\mathrm{ZnO}-\mathrm{Al}_{2} \mathrm{O}_{3} \quad$ Catalyst. Energy Technology, 4(5): 565-572. https://doi.org/10.1002/ente.201600022

[24] Mansour, S.A. (2013). Study of thermal stabilization for polystyrene/carbon nanocomposites via TG/DSC techniques. Journal of Thermal Analysis and Calorimetry, 112: 579-583. https://doi.org/10.1007/s10973-0122595-9

[25] Labii, T., Ceretti, M., Boubertakh, A., Paulus, W., Hamamda, S. (2012). Dilatometric study of $\mathrm{CaFeO}$. Journal of Thermal Analysis and Calorimetry, 112(2): 865-870. https://doi.org/10.1007/s10973-012-2690-y

[26] Auckett, J.E., McIntyre, G.J., Avdeev, M., De Bruyn, H., Tan, T.T., Li, S., Ling, C.D. (2015). Neutron Laue diffraction study of the complex low-temperature magnetic behaviour of brownmillerite-type $\mathrm{Ca}_{2} \mathrm{Fe}_{2} \mathrm{O}_{5}$. Journal of Applied Crystallography, 48(1): 273-279. https://doi.org/10.1107/S1600576714027976

[27] Revo, S., Rachiy, B., Hamamda, S., Avramenko, T., Ivanenko, K. (2012). Capacitance of supercapacitors with electrodes based on carbon nanocomposite material. Université Mentouri, 36: 9-13.

[28] Zafar, M., Najeeb, S., Khurshid, Z., Vazirzadeh, M., Zohaib, S., Najeeb, B., Sefat, F. (2016). Potential of electrospun nanofibers for biomedical and dental applications. $\quad$ Materials, $\quad 9(2)$ : $\quad 73$. https://doi.org/10.3390/ma9020073

[29] Apaydin-Varol, E., Polat, S., Putun, A.E. (2014). Pyrolysis kinetics and thermal decomposition behavior of polycarbonate-a TGA-FTIR study. Thermal Science, 18(3): 833-842. https://doi.org/10.2298/TSCI1403833A

[30] Wang, X., Zhao, Y., Hagiwara, M., Hou, H., Suzuki, T. (2010). Kinetics of dehydrogenation in Ti600, TC21 and Ti40 alloys. Journal of Alloys and Compounds, 490(1-2): 531-536. https://doi.org/10.1016/j.jallcom.2009.10.074 